\title{
Seasonal variation of serum 25-hydroxyvitamin D levels in adult patients with inflammatory bowel disease
}

\author{
P. H. A. Bours • J. P. M. Wielders • J. R. Vermeijden • \\ A. van de Wiel
}

Received: 23 July 2010 /Accepted: 1 November 2010 /Published online: 27 November 2010

(C) The Author(s) 2010. This article is published with open access at Springerlink.com

\begin{abstract}
Summary Patients with inflammatory bowel disease (IBD) are at risk of osteoporosis. Vitamin D (vitD) deficiency is known as a risk factor of osteoporosis. We observed low vitD blood levels in adult IBD patients both at the end of summer and winter. Furthermore, effects of oral vitD supplementation in (generally low) daily dosages were poor.

Introduction Patients with IBD are at risk of osteoporosis. This study evaluates seasonal vitD status, determinants of vitD deficiency and effects of vitD supplementation in adult IBD patients.

Methods Patients were screened for vitD deficiency at the end of summer and winter using serum $25 \mathrm{OHD}_{3}$ (cut-off point, $<50 \mathrm{nmol} / \mathrm{L}$ ) combined with routine laboratory tests. A standardized questionnaire was used for demographic/ lifestyle data i.e. IBD activity, health behaviour and vitD intake through diet and ultraviolet light.

Results Late-summer, $39 \%$ of the included 316 patients were vitD deficient. Late-winter, $57 \%$ of the follow-up patients ( $n=$ 281) were deficient. Independent protective determinants of vitD deficiency were oral vitD supplementation (summer/ winter: odds ratio [OR], 0.52 [95\% confidence interval [CI],
\end{abstract}

P. H. A. Bours $(\bowtie) \cdot J$. R. Vermeijden

Department of Gastroenterology and Hepatology,

Meander Medical Centre,

Amersfoort, The Netherlands

e-mail: pha.bours@gmail.com

J. P. M. Wielders

Department of Clinical Chemistry, Meander Medical Centre,

Amersfoort, The Netherlands

A. van de Wiel

Department of Internal Medicine, Meander Medical Centre,

Amersfoort, The Netherlands
0.29-0.94]/OR, 0.44 [95\% CI, 0.26-0.75]), recent sun holiday (summer: OR, 0.42 [95\% CI, 0.24-0.74]) and regular solarium visits (summer/winter: OR, 0.28 [95\% CI, $0.13-0.63] / \mathrm{OR}, 0.17[0.06-0.50])$. IBD activity $(p=0.031)$, red blood cell distribution width (RDW; $p=0.04)$ and erythrocyte sedimentation rate $(p=0.03)$ were associated with low vitD levels using univariate analyses of the extreme 25OHD quartiles. In a subgroup with vitD supplementation, still 30\% (late-summer) and $44 \%$ (late-winter) were vitD deficient.

Conclusion VitD deficiency is common in IBD patients, but prevalence might be comparable with the general population. Ultraviolet light is essential for adequate vitD levels. Effects of oral vitD supplementation in (generally low) daily dosages are poor. Determinants for low vitD levels were IBD activity and elevated inflammatory markers, suggesting that increased risk of osteoporosis in IBD might be more related to the inflammation than to vitD deficiency.

Keywords Inflammatory bowel disease - Osteoporosis . Pathophysiology $\cdot$ Prevalence $\cdot$ Seasonal variation $\cdot$ Serum 25-hydroxyvitamin D

\section{Introduction}

Patients with Crohn's disease (CD) and ulcerative colitis (UC), the two most common forms of inflammatory bowel disease (IBD), have an increased risk of developing osteoporosis [1,2]. Osteoporosis is characterized by a low bone mineral density and deteriorated micro-architecture of the skeleton, which leads to increased fracture risks [3]. The pathophysiology of IBD-related osteoporosis is presumably multifactorial and up to now not fully understood [3, 4]. 
Different pathways can be distinguished including the negative effects of glucocorticoid therapy, malnutrition leading to low body weight, systemic effects of chronic inflammatory reactions through pro-inflammatory cytokines and vitamin $\mathrm{D}$ deficiency.

Vitamin D deficiency is known as an important risk factor of osteoporosis in the general population and leads to increased bone resorption caused by secondary hyperparathyroidism [5]. Available literature concerning vitamin D deficiency and the seasonal variation of $25 \mathrm{OHD}$ levels in IBD is limited. Some authors reported high prevalence rates of vitamin D deficiency in IBD patients, especially in $\mathrm{CD}$, but these conclusions are based on relatively small sample sizes [6-10]. To our knowledge, little information is currently available on seasonal variation of vitamin D levels in both CD and UC patients.

In this prospective cohort study, we analysed the vitamin $\mathrm{D}$ status both at the end of the summer and winter period in adult IBD patients attending our gastroenterology department. Additionally, we investigated potential determinants of vitamin $\mathrm{D}$ deficiency and the effects of oral vitamin D supplementation.

\section{Materials and methods}

\section{Study population}

Patients aged 18 years or older and diagnosed with IBD who attended our gastroenterology department in the last 2 years $(n=459)$ were invited by mail to participate in this project. The diagnosis of IBD had to be confirmed on clinical grounds, with endoscopic and/or radiologic evidence, supported by histological mucosal findings according to the Lennard-Jones criteria [11]. Patients diagnosed with 'indeterminate colitis' were excluded from this study. All included patients were screened for vitamin D deficiency at the end of summer 2009 (SeptemberNovember) and winter 2009-2010 (January-March) at the gastroenterology outpatient department of a large teaching hospital in the centre of the Netherlands. Written informed consent was obtained from all participants. The study protocol was approved by the local Medical Ethics Committee of the Meander Medical Centre.

Data collection

A standardized questionnaire was used to analyse information on self-reported demographic data i.e. age, sex, ethnicity, health behaviour, physical activity, current smoking and alcohol usage. Physical activity was assessed using the SQUASH (Short QUestionnaire to ASess Health) questionnaire according to the national physical activity scale [12]. Excessive alcohol usage was defined as $>21$ alcoholic units per week for men and $>14$ alcoholic units per week for women. Disease activity of IBD was assessed by the Manitoba IBD index [13]. This index is based on patient self-reports enclosing IBD-related symptoms in the last 6 months. Other patient characteristics were retrieved from documented medical records in order to obtain data of fractures in the past and corticosteroid usage. Body mass index was measured by calculating weight in kilograms divided by the square height in meters. For their vitamin D assessment, patients had to undergo serum 25OHD measurement at the end of summer and winter and complete two questionnaires. In these questionnaires, patients were asked to report their daily oral vitamin D supplementation (including daily dosages and type of supplementation i.e. prescription medication and/or over the counter supplements), medication compliance, preferred exposure to sunlight or shade when outdoors and average number of days per week with $>2$ midday hours exposure to sunlight during summer. Furthermore, sun holidays in the last 6 months, frequency of solarium visits, calcium intake (dairy products /day) and intake of fatty fish (servings/ month), i.e. mackerel, herring and salmon, were assessed.

\section{Laboratory measurements}

Original serum samples were drawn in EDTA, respectively, heparin-containing collection tubes, centrifuged and stored at $-30^{\circ} \mathrm{C}$. Biochemical and haematological laboratory markers (e.g. haemoglobin $(\mathrm{Hb})$, haematocrit $(\mathrm{Ht})$, red blood cell distribution width (RDW), erythrocyte sedimentation rate (ESR), C-reactive protein (CRP), calcium, phosphate, alkaline phosphatase, albumin, creatinine and thyroid stimulating hormone) were measured at the end of summer (SeptemberNovember 2009). Serum $25 \mathrm{OHD}_{3}$ levels were analysed as indicator of the vitamin D status at the end of the summer (September-November 2009) and winter period (JanuaryMarch 2010) using an electrochemiluminescence immunoassay (ECLIA) from Roche on a Cobas E module (Roche Diagnostics ${ }^{\circledR}$, Penzberg, Germany). The between-run CV was $4.6 \%$ at $53 \mathrm{nmol} / \mathrm{L}$ and $9.9 \%$ at $28 \mathrm{nmol} / \mathrm{L}$. We defined $25 \mathrm{OHD}_{3}$ levels $<50 \mathrm{nmol} / \mathrm{L}(20 \mathrm{ng} / \mathrm{mL})$ as being vitamin $\mathrm{D}$ deficient.

Statistical analyses

Statistical analyses were performed using SPSS 17.0 (SPSS Inc., Chicago, IL, USA). For univariate comparison, 25OHD levels were stratified in two groups (vitamin $\mathrm{D}$ deficiency, $<50 \mathrm{nmol} / \mathrm{L}$, and adequate vitamin D status, $\geq 50 \mathrm{nmol} / \mathrm{L}$ ). Univariate statistical analyses were performed by using a parametric test (unpaired $t$ test) when a normal distribution was present and, when in 
order, a non-parametric test (Mann-Whitney $U$ ) to assess significant associations between the stated continuous determinants and the various groups (CD patients vs. UC patients, and vitamin D deficiency vs. adequacy). Categorical determinants were analysed by using Pearson's Chi-square test (or Fisher's exact test when expected frequencies were low). Furthermore, quartiles according the 25OHD levels were stratified and assessed using a one-way ANOVA test with a Bonferroni post hoc test as parametric test when a normal distribution was present, and a non-parametric test (Kruskal-Wallis test) when in order to assess significant associations between the stated determinants and 250HD quartiles. Mean differences between 25OHD levels in summer and winter were calculated with the non-parametric Wilcoxon signed rank test. In order to identify independent risk factors of vitamin D deficiency in summer and winter, a logistic regression model was used with vitamin $\mathrm{D}$ deficiency as dependent factor. All $p$ values $>0.10$ are noted in the tables as NS (non-significant). All $p$ values between 0.5 and 0.10 are noted in order to identify non-significant trends. All $p$ values $<0.05$ were considered as statistically significant.

\section{Results}

In this study, 316 patients with a mean age $( \pm \mathrm{SD})$ of $48.5 \pm 14.8$ years were included (Table 1). Fifty-seven percent of the included patients were women. Ninetyseven percent of the patients were of Caucasian ethnicity. The main group of IBD patients was diagnosed with UC $(59 \%)$. The mean duration of IBD $( \pm \mathrm{SD})$ was $11.0 \pm$ 9.7 years.

Vitamin D deficiency in summer and winter

At the end of summer, vitamin D deficiency was seen in $39 \%$ (95\% confidence interval [CI], 33.3-44.2) of the included IBD patients with a mean serum 250HD level of $55.1 \mathrm{nmol} / \mathrm{L}$ (Tables 2 and 3). Univariate analysis of vitamin $\mathrm{D}$ deficiency at the end of summer using $50 \mathrm{nmol} / \mathrm{L}$ as cut-off point resulted in the following significant predictors. Associations were found between an adequate vitamin $\mathrm{D}$ status and daily oral vitamin D supplementation $(p=0.029)$, smoking $(p=0.005)$, preferred sun exposure when outdoors $(p=0.020)$, regular solarium visits $(p=0.003)$ and sun holiday $(p<0.001)$. Predictive factors for vitamin D deficiency were high body mass index $(p=0.002)$ and the elevated biochemical marker alkaline phosphatase $(p=0.003)$. Late-summer, non-significant trends were found between vitamin D adequacy and the UC $(p=0.08)$, female gender $(p=$ $0.07)$ and the haematological marker RDW $(p=0.06)$.
In the follow-up measurement at the end of winter, serum 25OHD levels of 281 patients (loss to follow-up, $n=$ 35) were determined. In this follow-up group, $57 \%$ of the patients were vitamin $\mathrm{D}$ deficient with a mean serum $25 \mathrm{OHD}$ of $48.8 \mathrm{nmol} / \mathrm{L}$. The mean difference (CI) of 25OHD levels between summer and winter was $7.4 \mathrm{nmol} / \mathrm{L}$ (5.54-9.26 nmol/L), and 25OHD levels differed significantly between these two periods $(p<0.001)$ in our study population. Univariate analysis resulted in three significant determinants reducing the risk of vitamin D deficiency at the end of winter: oral vitamin D supplementation usage during winter $(p<0.001)$, sun holiday during winter $(p=$ $0.047)$ and regular solarium visits during winter ( $p=$ $0.012)$. At the end of summer and winter, no significant univariate associations were found between low serum vitamin D levels and age, gender, type of IBD (CD vs. UC), alcohol usage, disease duration and physical activity.

\section{Vitamin D quartiles}

By using univariate analyses of the vitamin D quartiles, several significant associations have been observed (Table 4). High body mass index $(p=0.010)$ and elevated blood levels of alkaline phosphatase $(p=0.022)$ were associated with low vitamin D levels. Preferred exposure to sun when outdoors $(p=0.003)$, sun holiday $(p<0.001)$, solarium visits $(p=0.020)$ and current smoking $(p=0.009)$ were associated with high vitamin D levels. Non-significant trends were observed between high vitamin D levels and daily oral vitamin D supplementation usage $(p=0.07)$, sufficient physical activity $(p=0.06)$ and elevated creatinine levels $(p=$ $0.08)$. Low vitamin D levels were non-significantly associated with increased fatty fish intake $(p=0.05)$. Furthermore, comparison of the lowest and highest quartile of vitamin D levels (serum $25 \mathrm{OHD},<42$ vs. $\geq 67 \mathrm{nmol} / \mathrm{L}$ ) led to the significant associations between low vitamin D levels and disease activity of IBD $(p=0.031)$ and elevated blood levels of RDW ( $p=0.04)$ and $\operatorname{ESR}(p=0.03)$.

\section{Multivariate analyses}

By using a logistic multivariate regression model, independent risk factors of vitamin D deficiency could be identified (Table 5). Based on the late-summer measurements, UC (odds ratio [OR], 0.55 [95\% CI, 0.31-0.95]), current smoking (OR, 0.27 [0.13-0.57]), oral vitamin D supplementation (OR, 0.52 [0.29-0.94]), recent sun holiday (OR, $0.42[0.24-0.74])$ and regular solarium visits (OR, 0.28 [0.13-0.63]) independently decreased the risk of being vitamin $\mathrm{D}$ deficient. Furthermore, high body mass index (OR, 1.11 [95\% CI, 1.05-1.19]) independently increased the risk of vitamin D deficiency. During winter, oral vitamin D supplementation (OR, 0.44 [0.26-0.75]) and 
Table 1 Baseline characteristics and laboratory results of IBD patients

\begin{tabular}{|c|c|c|c|c|}
\hline & $\begin{array}{l}\text { Total } \\
n=316\end{array}$ & $\begin{array}{l}\text { CD patients } \\
n=131\end{array}$ & $\begin{array}{l}\text { UC patients } \\
n=185\end{array}$ & $p$ value $^{\mathrm{a}}$ \\
\hline Age, years (SD) & $48.5(14.8)$ & $46.5(14.7)$ & $49.9(14.8)$ & 0.046 \\
\hline Women, $n(\%)$ & $181(57.3)$ & $84(64.1)$ & $97(52.4)$ & 0.039 \\
\hline Postmenopausal state, $n$ (\% of women) & $71(39.2)$ & $32(38.1)$ & $39(40.2)$ & NS \\
\hline Body mass index, kg/m² (SD) & $25.3(4.5)$ & $25.5(4.8)$ & $25.1(4.3)$ & NS \\
\hline Active IBD, $n(\%)$ & $160(50.6)$ & $70(53.4)$ & $90(48.6)$ & NS \\
\hline Disease duration IBD, years (SD) & $11.0(9.7)$ & $11.1(10.0)$ & $11.0(9.6)$ & NS \\
\hline Exacerbation IBD, episodes/year (SD) & $2.7(2.1)$ & $2.8(2.2)$ & $2.7(1.9)$ & NS \\
\hline History of $>7.5 \mathrm{mg}$ daily corticosteroid usage for at least 6 months, $n(\%)$ & $92(29.1)$ & $38(29.0)$ & $54(29.2)$ & NS \\
\hline Daily use of oral vitamin D supplementation, $n(\%)$ & $106(33.5)$ & $42(32.1)$ & $64(34.6)$ & NS \\
\hline Low dietary calcium intake, $n(\%)$ & $15(4.8)$ & $6(4.6)$ & $9(4.9)$ & NS \\
\hline Fatty fish intake, units/month (SD) & $2.6(2.5)$ & $2.6(2.3)$ & $2.7(2.5)$ & NS \\
\hline Excessive alcohol usage, $n(\%)$ & $34(10.9)$ & $11(8.5)$ & $23(12.6)$ & NS \\
\hline Current smoking, $n(\%)$ & $73(23.1)$ & $46(35.1)$ & $27(14.6)$ & $<0.001$ \\
\hline Preferred exposure to sun when outdoors, $n(\%)$ & $166(53.7)$ & $61(36.7)$ & $105(63.3)$ & 0.041 \\
\hline \multicolumn{5}{|l|}{ Outdoor activities at least $2 \mathrm{~h}$ a day } \\
\hline Summer, days/week (SD) & $4.5(2.1)$ & $5.4(2.1)$ & $5.4(2.1)$ & NS \\
\hline Winter, days/week (SD) & $3.0(2.5)$ & $3.1(2.5)$ & $2.9(2.4)$ & NS \\
\hline Sun holiday in the last year, $n(\%)$ & $138(44.5)$ & $49(37.7)$ & $89(49.4)$ & 0.040 \\
\hline Solarium visits, $n(\%)$ & $64(20.6)$ & $27(20.8)$ & $37(20.6)$ & NS \\
\hline \multicolumn{5}{|l|}{ Laboratory markers in serum } \\
\hline $\mathrm{Hb}, \mathrm{mmol} / \mathrm{L}(\mathrm{SD})$ & $8.6(0.92)$ & $8.5(0.90)$ & $8.7(0.93)$ & NS \\
\hline $\mathrm{Ht}, \mathrm{L} / \mathrm{L}(\mathrm{SD})$ & $0.41(0.04)$ & $0.40(0.04)$ & $0.41(0.04)$ & NS \\
\hline RDW, \% (SD) & $44.6(4.8)$ & $45.8(5.2)$ & $43.7(4.2)$ & $<0.001$ \\
\hline $\mathrm{ESR}, \mathrm{mm} / \mathrm{h}(\mathrm{SD})$ & $14.1(12.7)$ & $15.7(10.8)$ & $13.0(13.8)$ & $<0.001$ \\
\hline CRP, mg/L (SD) & $4.5(7.7)$ & $5.1(6.4)$ & $4.1(8.6)$ & $<0.001$ \\
\hline Calcium, mmol/L (SD) & $2.3(0.1)$ & $2.4(0.1)$ & $2.3(0.09)$ & NS \\
\hline Phosphate, mmol/L (SD) & $1.1(0.2)$ & $1.1(0.2)$ & $1.1(0.2)$ & NS \\
\hline Albumin, g/L (SD) & $40.6(3.2)$ & $40.1(3.2)$ & $40.9(3.2)$ & 0.006 \\
\hline Creatinine, $\mu \mathrm{mol} / \mathrm{L}(\mathrm{SD})$ & $72.9(15.7)$ & $71.2(13.7)$ & $74.2(16.8)$ & NS \\
\hline TSH, mIU/L (SD) & $1.53(0.87)$ & $1.50(0.95)$ & $1.54(0.81)$ & NS \\
\hline
\end{tabular}

$S D$ standard deviation, $H b$ haemoglobin, $H t$ haematocrit, $R D W$ red blood cell distribution width, ESR erythrocyte sedimentation rate, $C R P$ Creactive protein, TSH thyroid stimulating hormone

${ }^{a}$ Statistical analyses between CD and UC patients were performed by using a parametric test (unpaired $t$ test) when a normal distribution was present and when in order a non-parametric test (Mann-Whitney $U$ ) to assess univariate significant associations between the stated continuous determinants and CD vs. UC. Categorical determinants were analysed by using Pearson's Chi-square test (or Fisher's exact test when expected frequencies were low). All $p$ values $>0.10$ are noted as NS (non-significant). All $p$ values between 0.5 and 0.10 are noted in order to evaluate non-significant trends associated between the groups

regular solarium visits (OR, 0.17 [0.06-0.50]) were associated with a decreased risk of being vitamin D deficient.

\section{Vitamin D supplementation}

In this study population, 106 patients (34\%) used daily oral vitamin $\mathrm{D}$ supplementation (vitamin $\mathrm{D}_{3}$ : cholecalciferol) during summer with a mean daily dosage of $7.6 \mu \mathrm{g}$ (334 international units [IU]) ranging between 1.3 (57 IU) and $40 \mu \mathrm{g}$ (17.600 IU). Nevertheless, $27 \%$ of the patients with supplementation were still vitamin D deficient at the end of summer. During winter, 117 patients $(43 \%$ of $n=281$ ) used oral vitamin D supplements with a mean daily dosage of $9.5 \mu \mathrm{g}$ (418 IU). In this follow-up group, still 53 patients (45\%) with vitamin D supplementation were vitamin D deficient. Patients who used oral vitamin D supplementation in combination with additional ultraviolet light exposure (through sun holidays or solarium visits) had mean serum $25 \mathrm{OHD}$ levels of $61.3 \mathrm{nmol} / \mathrm{L}$ at the end of summer and $55.7 \mathrm{nmol} / \mathrm{L}$ at the end of winter. Patients without any additional vitamin D intake through oral supplementation 
Table 2 Determinants of vitamin D status in IBD patients late-summer

\begin{tabular}{|c|c|c|c|}
\hline & $\begin{array}{l}\text { Vitamin D } \\
\text { deficiency }<50 \mathrm{nmol} / \mathrm{L} \\
n=122\end{array}$ & $\begin{array}{l}\text { Vitamin D } \\
\text { adequacy } \geq 50 \mathrm{nmol} / \mathrm{L} \\
n=194\end{array}$ & $p$ value $^{\mathrm{a}}$ \\
\hline Ulcerative colitis, $n(\%)$ & $64(52.2)$ & $121(62.4)$ & 0.08 \\
\hline Age, years (SD) & $48.6(14.7)$ & $48.5(14.9)$ & NS \\
\hline Women, $n(\%)$ & $62(50.8)$ & $119(61.3)$ & 0.07 \\
\hline Postmenopausal state, $n$ ( $\%$ of women) & $28(45.2)$ & $43(36.1)$ & NS \\
\hline Body mass index, $\mathrm{kg} / \mathrm{m}^{2}$ (SD) & $26.5(5.3)$ & $24.4(3.7)$ & 0.002 \\
\hline Active IBD, $n(\%)$ & $67(54.9)$ & $93(47.9)$ & NS \\
\hline Disease duration IBD, years (SD) & $11.3(10.8)$ & $10.9(9.0)$ & NS \\
\hline Exacerbation IBD, episodes/year (SD) & $2.8(2.1)$ & $2.7(2.0)$ & NS \\
\hline History of $>7.5 \mathrm{mg}$ daily corticosteroid usage for at least 6 months, $n(\%)$ & $42(34.4)$ & $50(25.8)$ & NS \\
\hline Excessive alcohol usage, $n(\%)$ & $10(8.4)$ & $24(12.5)$ & NS \\
\hline Sufficient physical activity, $n(\%)$ & $67(54.9)$ & $93(47.9)$ & NS \\
\hline Current smoking, $n(\%)$ & $17(13.9)$ & $56(28.9)$ & 0.005 \\
\hline Preferred exposure to sun when outdoors, $n(\%)$ & $53(45.3)$ & $113(58.9)$ & 0.020 \\
\hline \multicolumn{4}{|l|}{ Laboratory markers in serum } \\
\hline $\mathrm{Hb}, \mathrm{mmol} / \mathrm{L}(\mathrm{SD})$ & $8.7(0.9)$ & $8.6(0.9)$ & NS \\
\hline $\mathrm{Ht}, \mathrm{L} / \mathrm{L}(\mathrm{SD})$ & $0.41(0.04)$ & $0.41(0.04)$ & NS \\
\hline RDW, \% (SD) & $45.3(5.6)$ & $44.2(4.1)$ & 0.06 \\
\hline $\mathrm{ESR}, \mathrm{mm} / \mathrm{h}(\mathrm{SD})$ & $14.9(13.4)$ & $13.7(12.2)$ & NS \\
\hline CRP, mg/L (SD) & $4.3(5.7)$ & $4.7(8.8)$ & NS \\
\hline Calcium, mmol/L (SD) & $2.4(0.1)$ & $2.4(0.1)$ & NS \\
\hline Phosphate, mmol/L (SD) & $1.1(0.2)$ & $1.1(0.2)$ & NS \\
\hline Alkaline phosphatase, IU/L (SD) & $79.6(21.9)$ & $75.2(31.9)$ & 0.003 \\
\hline Albumin, g/L (SD) & $40.7(3.0)$ & $40.5(3.4)$ & NS \\
\hline Creatinine, $\mu \mathrm{mol} / \mathrm{L}$ (SD) & $73.3(15.5)$ & $72.7(15.8)$ & NS \\
\hline TSH, mIU/L (SD) & $1.6(1.0)$ & $1.5(0.8)$ & NS \\
\hline
\end{tabular}

${ }^{\text {a }}$ Statistical analyses were performed by using a parametric test (unpaired $t$ test) when a normal distribution was present and when in order a non-parametric test (Mann-Whitney $U$ ) to assess univariate significant associations between the stated continuous determinants and vitamin D deficiency. Categorical determinants were analysed by using Pearson's Chi-square test (or Fisher's exact test when expected frequencies were low). All $p$ values $>0.10$ are noted as NS (non-significant). All $p$ values between 0.5 and 0.10 are noted in order to evaluate non-significant trends associated with vitamin D deficiency

or sun exposure had lower mean serum 25OHD levels of $48.4 \mathrm{nmol} / \mathrm{L}$ at the end of summer and $42.7 \mathrm{nmol} / \mathrm{L}$ at the end of winter (Fig. 1).

In general, a decreased risk of vitamin D deficiency was seen in patients who used daily oral vitamin D supplementation during summer $(p=0.029)$ and winter $(p<0.001)$. Higher dosages of supplementation did not lower the risk of developing vitamin D deficiency, although a nonsignificant negative trend was seen between the daily dosage of vitamin $\mathrm{D}$ supplementation and the risk of being vitamin $\mathrm{D}$ deficient $(p=0.09)$.

\section{Discussion}

This prospective cohort study demonstrates that vitamin D deficiency, with a prevalence of $39 \%$ at the end of summer, is a common problem in IBD patients. Furthermore, strong seasonal variation of vitamin D levels was observed, with a decline of mean serum $25 \mathrm{OHD}$ levels from $55.1 \mathrm{nmol} / \mathrm{L}$ at the end of summer to $48.4 \mathrm{nmol} / \mathrm{L}$ at the end of winter, leading to an overall vitamin D deficiency prevalence of $57 \%$ in the sun-deprived months. To our knowledge, this is the largest study up till now which investigates the seasonality of vitamin D levels in a cohort of adult IBD outpatients. Our results are in line with the few data currently available concerning vitamin D deficiency in IBD patients. McCarthy et al. described in $44 \mathrm{CD}$ patients prevalence rates of vitamin D deficiency of $18 \%$ (cut-off point, $<50 \mathrm{nmol} / \mathrm{L}$ ) late-summer and 50\% late-winter [14]. Kuwabara et al. reported vitamin D deficiency prevalence rates of even $76 \%$ in $70 \mathrm{IBD}$ patients at the end of summer (cut-off point, $<50 \mathrm{nmol} / \mathrm{L}$ ) [10]. Generally, we can conclude that our study, which is characterized by a large 
Table 3 Determinants of vitamin D status in IBD patients stratified by season

\begin{tabular}{|c|c|c|c|c|c|c|c|c|}
\hline & \multicolumn{3}{|c|}{ End of summer } & \multicolumn{3}{|c|}{ End of winter } & \multirow{2}{*}{\multicolumn{2}{|c|}{$\begin{array}{l}p \text { values }^{\mathrm{a}} \\
\text { Vitamin D } \\
\text { deficiency vs. } \\
\text { adequacy }\end{array}$}} \\
\hline & Total & $\begin{array}{l}\text { Vitamin D } \\
\text { deficiency } \\
<50 \mathrm{nmol} / \mathrm{L}\end{array}$ & $\begin{array}{l}\text { Vitamin D } \\
\text { adequacy } \\
\geq 50 \mathrm{nmol} / \mathrm{L}\end{array}$ & Total & $\begin{array}{l}\text { Vitamin D } \\
\text { deficiency } \\
<50 \mathrm{nmol} / \mathrm{L}\end{array}$ & $\begin{array}{l}\text { Vitamin D } \\
\text { adequacy } \\
\geq 50 \mathrm{nmol} / \mathrm{L}\end{array}$ & & \\
\hline & $n=316$ & $n=122$ & $n=194$ & $n=281$ & $n=160$ & $n=121$ & Summer & Winter \\
\hline $\begin{array}{l}\text { Oral vitamin } \mathrm{D} \\
\quad \text { supplementation, } n(\%)\end{array}$ & $106(33.5)$ & $32(26.6)$ & $74(38.1)$ & $117(43.5)$ & $53(34.6)$ & $64(55.2)$ & 0.029 & $<0.001$ \\
\hline $\begin{array}{l}\text { Fatty fish intake, } \\
\text { units/month (SD) }\end{array}$ & $2.6(2.5)$ & $2.7(2.8)$ & $2.5(2.0)$ & $2.6(2.2)$ & $2.8(2.4)$ & $2.5(2.0)$ & NS & NS \\
\hline $\begin{array}{l}\text { Outdoor activities at least } \\
2 \mathrm{~h} \text { a day, days/week } \\
\text { (SD) }\end{array}$ & $5.4(2.1)$ & $5.3(2.1)$ & $5.5(2.1)$ & $3.0(2.5)$ & $3.1(2.5)$ & $2.9(2.5)$ & NS & NS \\
\hline Recent sun holiday, $n(\%)$ & $138(44.5)$ & $39(33.1)$ & $99(51.6)$ & $28(10.1)$ & $11(7.0)$ & $17(14.3)$ & $<0.001$ & 0.047 \\
\hline $\begin{array}{l}\text { Regular solarium } \\
\text { visits, } n(\%)\end{array}$ & $64(20.6)$ & $14(11.9)$ & $50(26.0)$ & $28(10.1)$ & $7(4.5)$ & $21(17.6)$ & 0.003 & 0.012 \\
\hline $\begin{array}{l}\text { Serum 25OHD level, } \\
\mathrm{nmol} / \mathrm{L}(\mathrm{SD})\end{array}$ & $55.1(16.4)$ & $39.1(7.8)$ & $65.1(11.8)$ & $48.4(20.0)$ & $35.6(11.0)$ & $65.5(16.0)$ & - & - \\
\hline
\end{tabular}

${ }^{\text {a }}$ Statistical analyses were performed by using a parametric test (unpaired $t$ test) when a normal distribution was present and when in order a non-parametric test (Mann-Whitney $U$ ) to assess univariate significant associations between the stated continuous determinants and vitamin D deficiency. Categorical determinants were analysed by using Pearson's Chi-square test (or Fisher's exact test when expected frequencies were low). All $p$ values $>0.10$ are noted as NS (non-significant). All $p$ values between 0.5 and 0.10 are noted in order to evaluate non-significant trends associated with vitamin D deficiency

and representative IBD outpatient cohort, confirms the high prevalence of vitamin D deficiency which was presumed in preliminary studies.

Prevalence rates of vitamin D deficiency in the general population are better documented compared to the relatively small subgroup of IBD patients; unfortunately, the usefulness of these prevalence data for comparison with our diseased group is limited. In the Netherlands, representative population-based studies are lacking. Comparison between studies, specifically between different countries, is further hampered by differences in study designs, latitude, age and the lack of international consensus on serum 25OHD cut-off levels [15-17]. Recently, a populationbased survey performed by Hinztpeter et al. in Germany which included over 4,000 adults reported that 57\% (95\% CI, 55.5-58.5) of the participants had serum 25OHD levels $<50 \mathrm{nmol} / \mathrm{L}$ [18]. In Great Britain, a population-based study performed by Hyppönen et al. reported comparable data with a mean 25OHD level of $60.3 \mathrm{nmol} / \mathrm{L}(95 \% \mathrm{CI}, 59.5-61.0)$ and $15 \%(95 \% \mathrm{CI}$, 14.4-16.5) of the included 45-year-old participants with serum $25 \mathrm{OHD}$ levels $<40 \mathrm{nmol} / \mathrm{L}$ [19]. Although we are aware of the fact that comparison between our study results and existing evidence is hampered by methodological differences, it seems that prevalence rates of vitamin D deficiency in our study population of Dutch IBD patients might be comparable with prevalence rates in the general population of neighbouring countries.
Exposure to ultraviolet light

Seasonal variation of serum 25OHD is caused by the strong dependence on the exposure to sunlight, especially in people living at high latitudes. Ultraviolet light stimulates the conversion of 7-dehydrocholesterol to cholecalciferol (vitamin $\mathrm{D}_{3}$ ) in the skin and is therefore essential for optimal vitamin D levels [20]. With regard to the $25 \mathrm{OHD}_{3}$ half-life of 2 months, the highest annual vitamin D levels in the northern hemisphere are expected in August/September and the lowest in February/March [21]. This annual variation has been observed by Hintzpeter et al. reporting maximum serum 25OHD levels in September and minimum levels in March [18]. The important physiologic effects of ultraviolet light are directly reflected in our results concerning the determinants for vitamin D deficiency. In summer, ultraviolet exposure in terms of preferred sun exposure when outdoors $(p=0.020)$, regular solarium visits $(p=0.003)$ and sun holidays in the last 6 months $(p<0.001)$ are of importance for adequate vitamin D levels. During winter, the participants had to rely on the exposure to ultraviolet light by regular solarium visits $(p<0.001)$ or visiting sunny holiday destinations $(p=$ 0.047 ) to obtain an adequate vitamin D status.

Dietary intake, smoking and body mass index

In the Netherlands, only a few nutritional products (i.e. fatty fish and margarine) contain vitamin $\mathrm{D}_{3}$ (Dutch dietary 
Table 4 Patient characteristics stratified by vitamin D quartiles measured at the end of summer

\begin{tabular}{|c|c|c|c|c|c|}
\hline & \multicolumn{4}{|c|}{ 25OHD quartiles, $\mathrm{nmol} / \mathrm{L}$} & \multirow[t]{2}{*}{$p$ value $^{\mathrm{a}}$} \\
\hline & $\begin{array}{l}\leq 42 \mathrm{nmol} / \mathrm{L} \\
n=79\end{array}$ & $\begin{array}{l}43-53 \mathrm{nmol} / \mathrm{L} \\
n=78\end{array}$ & $\begin{array}{l}54-66 \mathrm{nmol} / \mathrm{L} \\
n=81\end{array}$ & $\begin{array}{l}\geq 67 \mathrm{nmol} / \mathrm{L} \\
n=78\end{array}$ & \\
\hline Ulcerative colitis, $n(\%)$ & $39(49.4)$ & $46(59.0)$ & $53(65.4)$ & $47(60.3)$ & NS \\
\hline Age, years (SD) & $48.3(14.3)$ & $48.9(14.9)$ & $50.4(15.7)$ & $46.4(14.3)$ & NS \\
\hline Women, $n(\%)$ & $42(53.2)$ & $38(48.7)$ & $49(60.5)$ & $52(66.7)$ & NS \\
\hline Postmenopausal state, $n$ ( $\%$ of women) & $20(47.6)$ & $13(34.2)$ & $20(40.8)$ & $18(34.6)$ & NS \\
\hline Body mass index, $\mathrm{kg} / \mathrm{m}^{2}$ (SD) & $26.2(5.3)$ & $26.3(4.8)$ & $24.5(3.7)$ & $24.0(3.6)$ & 0.010 \\
\hline Active IBD, $n(\%)$ & $47(59.5)$ & $38(48.7)$ & $42(51.9)$ & $33(42.3)$ & NS \\
\hline Disease duration IBD, years (SD) & $11.3(10.9)$ & $10.4(9.5)$ & $12.2(9.9)$ & $10.2(8.5)$ & NS \\
\hline Exacerbation IBD, episodes/year (SD) & $2.9(2.2)$ & $2.8(1.9)$ & $2.7(2.3)$ & $2.6(1.9)$ & NS \\
\hline $\begin{array}{l}\text { History of }>7.5 \mathrm{mg} \text { daily corticosteroid } \\
\text { usage for at least six months, } n(\%)\end{array}$ & $31(39.2)$ & $19(24.4)$ & $23(28.4)$ & $19(24.4)$ & NS \\
\hline Daily use of oral vitamin D supplementation, $n(\%)$ & $22(27.8)$ & $21(26.9)$ & $36(44.4)$ & $27(34.6)$ & 0.07 \\
\hline Low dietary calcium intake, $n(\%)$ & $3(3.8)$ & $5(6.4)$ & $5(6.2)$ & $2(2.6)$ & NS \\
\hline Fatty fish intake, units/month (SD) & $2.2(2.0)$ & $3.4(3.2)$ & $2.6(2.0)$ & $2.4(2.4)$ & 0.05 \\
\hline Excessive alcohol usage, $n(\%)$ & $6(7.8)$ & $8(10.4)$ & $10(12.3)$ & $10(13.2)$ & NS \\
\hline Current smoking, $n(\%)$ & $8(10.1)$ & $19(24.4)$ & $22(27.2)$ & $24(30.8)$ & 0.009 \\
\hline Preferred exposure to sun when outdoors, $n(\%)$ & $29(37.7)$ & $43(57.3)$ & $38(47.5)$ & $56(72.7)$ & 0.003 \\
\hline Outdoor activities at least two hours a day, days/week (SD) & $5.1(2.3)$ & $5.5(1.9)$ & $5.6(2.1)$ & $5.4(2.3)$ & NS \\
\hline Sufficient physical activity, $n(\%)$ & $66(83.5)$ & $73(93.6)$ & $68(84.0)$ & $73(93.6)$ & 0.06 \\
\hline Sun holiday in the last year, $n(\%)$ & $26(33.3)$ & $23(30.7)$ & $40(50.0)$ & $49(63.3)$ & $<0.001$ \\
\hline Solarium visits, $n(\%)$ & $9(11.5)$ & $13(17.3)$ & $18(22.5)$ & $24(31.2)$ & 0.020 \\
\hline \multicolumn{6}{|l|}{ Laboratory markers in serum } \\
\hline $\mathrm{Hb}, \mathrm{mmol} / \mathrm{L}(\mathrm{SD})$ & $8.6(1.0)$ & $8.7(0.9)$ & $8.6(1.0)$ & $8.6(0.8)$ & NS \\
\hline $\mathrm{Ht}, \mathrm{L} / \mathrm{L}(\mathrm{SD})$ & $0.41(0.04)$ & $0.41(0.03)$ & $0.41(0.04)$ & $0.40(0.03)$ & NS \\
\hline RDW, \% (SD) & $45.5(5.5)$ & $44.1(4.8)$ & $44.7(4.5)$ & $44.0(3.9)$ & NS \\
\hline $\mathrm{ESR}, \mathrm{mm} / \mathrm{h}(\mathrm{SD})$ & $16.3(15.5)$ & $14.3(12.1)$ & $13.9(13.6)$ & $12.0(8.3)$ & NS \\
\hline CRP, mg/L (SD) & $4.6(5.7)$ & $4.6(7.5)$ & $4.4(10.5)$ & $4.6(6.3)$ & NS \\
\hline Calcium, mmol/L (SD) & $2.4(0.1)$ & $2.3(0.1)$ & $2.4(0.1)$ & $2.3(0.1)$ & NS \\
\hline Phosphate, mmol/L (SD) & $1.1(0.2)$ & $1.1(0.1)$ & $1.1(0.2)$ & $1.1(0.2)$ & NS \\
\hline Alkaline phosphatase, IU/L (SD) & $79.1(20.0)$ & $82.4(39.6)$ & $71.4(23.3)$ & $74.9(26.5)$ & 0.022 \\
\hline Albumin, g/L (SD) & $40.7(3.2)$ & $40.4(3.3)$ & $40.4(3.2)$ & $40.7(3.3)$ & NS \\
\hline Creatinine, $\mu \mathrm{mol} / \mathrm{L}$ (SD) & $72.1(15.4)$ & $75.9(15.7)$ & $74.2(17.2)$ & $69.3(13.6)$ & 0.08 \\
\hline TSH, mIU/L (SD) & $1.5(0.8)$ & $1.7(1.0)$ & $1.4(0.6)$ & $1.5(0.9)$ & NS \\
\hline
\end{tabular}

$S D$ standard deviation, $H b$ haemoglobin, $H t$ haematocrit, $R D W$ red blood cell distribution width, ESR erythrocyte sedimentation rate, $C R P$ Creactive protein, $T S H$ thyroid stimulating hormone

${ }^{\text {a }}$ Statistical analyses were performed by using one-way ANOVA with a Bonferroni post hoc test as parametric test when a normal distribution was present and when in order a non-parametric test (Kruskal-Wallis test) to assess univariate significant associations between the stated determinants and 25OHD quartiles. All $p$ values $>0.10$ are noted as NS (non-significant). All $p$ values between 0.5 and 0.10 are noted in order to evaluate non-significant trends associated with $25 \mathrm{OHD}$ quartiles

products do not contain vitamin $\mathrm{D}_{2}$ ), and the intake of dietary sources is minimal $[17,22]$. The effects of dietary intake of vitamin $\mathrm{D}$ are relatively poor in this study, resulting in no significant effects of fatty fish intake in summer or winter. Concerning lifestyle factors, the highly significant positive effect of smoking on vitamin D levels is remarkable. To our knowledge, no physiologic mechanism exists which can explain this extraordinary association, and these results may be caused by measurement interferences. Recently, Grimnes et al. reported an overestimation of 25OHD levels in assays of smokers compared to nonsmokers measured with the ECLIA (Roche) method [23]. This phenomenon is caused by an up till now unknown mechanism and should be evaluated by biochemical 
Table 5 Odds ratios for potential determinants of vitamin D deficiency at the end of summer and winter

\begin{tabular}{llc}
\hline & \multicolumn{1}{l}{ Odds ratio $(95 \% \mathrm{CI})$} & Winter $^{\mathrm{b}}$ \\
\cline { 2 - 3 } & Summer $^{\mathrm{a}}$ & $0.99(0.97-1.01)$ \\
\hline Age & $0.97(0.95-1.00)$ & $0.78(0.45-1.38)$ \\
Female gender & $0.59(0.34-1.03)$ & $0.91(0.53-1.56)$ \\
Ulcerative colitis & $0.55(0.31-0.95)$ & $-{ }^{\mathrm{c}}$ \\
Active IBD & $1.50(0.87-2.57)$ & $-{ }^{\mathrm{c}}$ \\
Body mass index & $1.11(1.05-1.19)$ & $-{ }^{\mathrm{c}}$ \\
Current smoking & $0.27(0.13-0.57)$ & $-{ }^{\mathrm{c}}$ \\
Alkaline phosphatase & $1.00(0.99-1.01)$ & $-{ }^{\mathrm{c}}$ \\
Preferred exposure to sun when outdoors & $0.81(0.47-1.41)$ & $0.44(0.26-0.75)$ \\
Oral vitamin D supplementation & $0.52(0.29-0.94)$ & $0.48(0.20-1.14)$ \\
Recent sun holiday & $0.42(0.24-0.74)$ & $0.17(0.06-0.50)$ \\
Regular solarium visits & $0.28(0.13-0.63)$ & $1.05(0.93-1.18)$ \\
Fatty fish intake & $0.99(0.89-1.10)$ & $1.01(0.91-1.13)$ \\
Outdoor activities at least $2 \mathrm{~h}$ a day & $0.97(0.86-1.10)$ & \\
\hline
\end{tabular}

Analyses were done by using logistic regression with vitamin D deficiency (cut-off point, $50 \mathrm{nmol} / \mathrm{L}$ ) in summer and winter as dependent variables

${ }^{\text {a }}$ Summer model: adjusted for age, gender, type of IBD, disease activity of IBD, body mass index, current smoking, alkaline phosphatase, preferred exposure to sun when outdoors, oral vitamin D supplementation during summer, recent sun holidays during summer, regular solarium visits during summer, fatty fish intake during summer and outdoor activities during summer

${ }^{\mathrm{b}}$ Winter model: adjusted for age, gender, type of IBD, oral vitamin D supplementation during winter, recent sun holidays during winter, regular solarium visits during winter, fatty fish intake during winter and outdoor activities during winter

${ }^{\mathrm{c}}$ Determinant not included in the logistic regression winter model
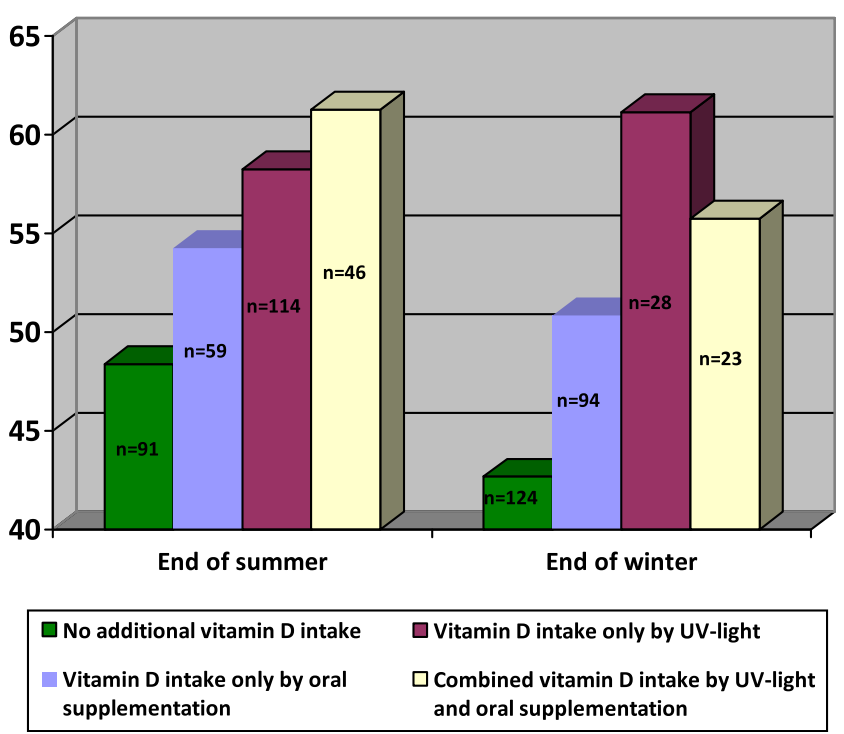

Fig. 1 Mean serum 25OHD levels (nanomoles per litre) at the end of summer and winter. Patients were classified as 'vitamin D intake only by ultraviolet (UV) light' if they did not use oral vitamin D supplementation and met one or two of the following criteria: regular solarium visits and sun holiday in the last 6 months. Patients who used oral supplementation without being exposed to ultraviolet light (no solarium visits or sun holidays) were classified as 'vitamin D intake only by oral supplementation'. If patients used both oral supplementation and additional UV light, they were classified as 'combined vitamin D intake by UV light and oral supplementation' measurement studies in the near future. Considering body mass index, our results show, in accordance with previous studies, a strong association between high body mass index and low vitamin D levels [24]. This supports the hypothesis that an increase of body mass index leads to a larger distribution volume in the body for the fat-soluble vitamin $\mathrm{D}$ which lowers the serum 25OHD concentration.

\section{Vitamin D supplementation}

In our study population, oral vitamin D supplementation is significantly associated with a decreased risk of vitamin $\mathrm{D}$ deficiency in summer $(p=0.029)$ and winter $(p<0.001)$. Nevertheless, the effects of vitamin D supplementation are far from satisfactory with the generally low dosages used in this study, where daily intake does not exceed 200-400 IU/ day. At the end of summer, $30 \%$ of the patients using supplementation were still vitamin D deficient. At the end of winter, even $44 \%$ of the vitamin D supplemented patients had serum $25 \mathrm{OHD}<50 \mathrm{nmol} / \mathrm{L}$. The fact that only a non-significant trend and not a significant relation could be observed between higher dosages and serum 25OHD levels is probably caused by the low dosages of vitamin D supplementation in this study population. This year, Jørgensen et al. published one of the first randomized placebo-controlled trials among $108 \mathrm{CD}$ patients to assess 
the effects of 1,200 IU cholecalciferol daily on CD activity [25]. The investigators concluded that these vitamin D dosages decreased disease activity and, more importantly, were safe to use. With regard to fracture risk reduction, various meta-analyses reported a decrease of fracture risk of $13 \%$ to $26 \%$ with $700-800$ IU vitamin D daily [26]. In contrast to the general consensus, Sanders et al. recently reported that one annual mega dosage of 600,000 IU cholecalciferol caused an increase of falls and fractures among 2,256 postmenopausal women [27]. Although the biological mechanisms of these findings are unclear, they indicate that the dosing regimen of cholecalciferol is important, and infrequent extreme doses are counterproductive in decreasing fracture risk. Taking the existing evidence into account, it is without doubt of major importance to prevent bone fractures by vitamin D supplementation which is frequently administered (i.e. daily, weekly or monthly). Although the optimal vitamin D supplementation dosages remain unclear, various authors state that the currently prescribed dosages are generally too low and can be raised up to 4,000 IU/day without any adverse effects $[25,28-31]$. Our results on vitamin D supplementation support the need of further studies for optimal vitamin D dosages in the general population and specifically for the IBD subgroup.

\section{Role of inflammatory process}

The association in our study between vitamin D deficiency and active IBD disease (including the increased haematological markers ESR and RDW), which was observed in univariate analyses of the lowest and highest vitamin D quartiles, is particularly interesting. Lately, RDW attracted attention because of its potential correlation with immunologic activity, which is interesting in chronic inflammatory diseases. In line with our baseline results, which show a significant higher RDW value in $\mathrm{CD}$ patients than in $\mathrm{UC}$ patients, one pilot study reported that RDW has the ability to differentiate between CD and UC [32]. Others proved that high RDW values are significantly correlated to alternated CRP and ESR levels showing that it can detect inflammatory processes in the human body [33].

Interest in vitamin $\mathrm{D}$ increased after the identification of vitamin D receptors (VDRs) in most tissues and cells in the body and discovery of the importance of the active metabolite (calcitriol) as a potent immunomodulator [22, 34]. Recently, vitamin $\mathrm{D}$ deficiency was found to be associated with increased incidences of cardiovascular disease, hypertension and cancer [35-38]. Poor vitamin D status has already been linked to auto-immune diseases like diabetes type 1 , multiple sclerosis and rheumatoid arthritis [39]. The association between IBD activity and vitamin $\mathrm{D}$ has been described in animal studies by some authors but is rarely reported in human studies [34,
40, 41]. Concerning CD patients, a new hypothesis states that vitamin $\mathrm{D}$ deficiency is not only the consequence but also a cause of the inflammatory process leading to bone loss through a Th1-driven immune response [42]. This hypothesis is recently supported by findings of an essential function of VDR in the protection of the colonic mucosa by regulating intestinal homeostasis in response to enteric bacterial invasion and commensal bacterial colonization [43]. In addition, an improvement of bone status and a decrease in IBD activity after therapy with 1,25-dihydroxyvitamin $\mathrm{D}$ was described in CD patients [44]. Although significant progression has been made concerning the role of vitamin D and its receptor, the exact mechanism is not yet fully understood and could lead to a new breakthrough concerning the aetiology of IBD.

The above-mentioned results on disease activity and vitamin $D$ deficiency indicate that increased risk of osteoporosis in IBD patients may not be caused by vitamin D deficiency only. In our opinion, it is plausible that the inflammatory process itself (which may be causally connected with vitamin D status in the aetiology of IBD) might lead to a negative effect on bone status through pro-inflammatory immunologic responses or a direct action of interleukins on the osteoclast activity. This perspective is endorsed by Tilg et al., who suggested in a recent review concerning the role of intestinal inflammation on bone health that pro-inflammatory cytokines (TNF $\alpha$, IL-1 $\beta$, IL-6 and interferon gamma (IFN $\gamma)$ ) which are involved in IBD not only cause mucosal (or systemic) inflammation but might cause bone loss as well [45].

\section{Study limitations}

A weakness in our study is that therapy compliance was assessed without regularly monitoring 25OHD serum levels. Although patients stated their supplementation usage in a questionnaire, which was only seen by the researcher and not by their own gastroenterologist, it is likely that compliance is lower than declared. Therapy compliance of vitamin D supplementation is more or less comparable with bisphosphonate therapy because patients do not directly notice the benefits of therapy. Poor therapy compliance of bisphosphonate is recently described in a meta-analysis by Imaz et al. showing that only $66 \%$ of the osteoporosis patients possessed their prescribed medication after 1 year of follow-up [46]. Whether low vitamin D levels despite supplementation are caused by ineffective vitamin D dosages, therapy compliance or other risk factors, the present study shows that vitamin D supplementation is suboptimal in IBD patients.

Furthermore, it is plausible that the correlation between disease activity and the assessed inactive vitamin D metabolites (25OHD) could be distorted by inflammatory reactions influencing the $25 \mathrm{OHD}$ level without affecting the function of the active 1,25-dihydroxyvitamin D metabolite. 
It is known that the circulation of 25OHD in serum depends on proteins, such as the carrier vitamin binding protein (DBP), of which concentrations may alter caused by pro- and antiinflammatory reactions. Nevertheless, in our view, it is rather unlikely that DBP concentrations will drop beneath the minimal concentration needed for $25 \mathrm{OHD}$ binding, due to the fact that 25OHD uses only a small amount of the binding sites of DBP available in the human body [47].

In conclusion, vitamin D deficiency is a common problem as shown in this large sample of adults suffering from IBD. Nevertheless, prevalence rates of vitamin D deficiency in IBD patients might be comparable to the prevalence in the general population. The importance of exposure to ultraviolet light for an adequate vitamin $\mathrm{D}$ status is subscribed by the observed seasonal variation of serum $25 \mathrm{OHD}$ levels between summer and winter. At the end of winter, the number of patients with vitamin D deficiency is increased by $50 \%$. Preferred sun exposure, sun holidays and solarium visits during summer and winter were strongly associated with high vitamin D levels. Factors associated with low vitamin D levels are high disease activity of IBD, high body mass index and increased haematological markers (ESR and RDW), indicating that the increased risk of osteoporosis in IBD is more related to the inflammatory process than to vitamin D deficiency. The effects of oral vitamin D supplementation on serum 25OHD are poor. Therefore, optimal vitamin D supplementation dosages in IBD patients should be reevaluated in future studies.

\section{Conflicts of interest None.}

Open Access This article is distributed under the terms of the Creative Commons Attribution Noncommercial License which permits any noncommercial use, distribution, and reproduction in any medium, provided the original author(s) and source are credited.

\section{References}

1. Vestergaard P (2004) Prevalence and pathogenesis of osteoporosis in patients with inflammatory bowel disease. Minerva Med 95:469-480

2. Schoon EJ, van Nunen AB, Wouters RS, Stockbrugger RW, Russel MG (2000) Osteopenia and osteoporosis in Crohn's disease: prevalence in a Dutch population-based cohort. Scand J Gastroenterol Suppl 232:43-47

3. Ali T, Lam D, Bronze MS, Humphrey MB (2009) Osteoporosis in inflammatory bowel disease. Am J Med 122:599-604. doi:10.1016/j.amjmed.2009.01.022

4. Bernstein CN, Leslie WD (2004) Review article: osteoporosis and inflammatory bowel disease. Aliment Pharmacol Ther 19:941952. doi:10.1111/j.1365-2036.2004.01876.x

5. Holick MF (2007) Optimal vitamin D status for the prevention and treatment of osteoporosis. Drugs Aging 24:1017-1029
6. Jahnsen J, Falch JA, Mowinckel P, Aadland E (2002) Vitamin D status, parathyroid hormone and bone mineral density in patients with inflammatory bowel disease. Scand J Gastroenterol 37:192199

7. Pappa HM, Gordon CM, Saslowsky TM, Zholudev A, Horr B, Shih MC, Grand RJ (2006) Vitamin D status in children and young adults with inflammatory bowel disease. Pediatrics 118:1950-1961. doi:10.1542/peds.2006-0841

8. Souza HN, Lora FL, Kulak CA, Manas NC, Amarante HM, Borba VZ (2008) Low levels of 25-hydroxyvitamin D (25OHD) in patients with inflammatory bowel disease and its correlation with bone mineral density. Arq Bras Endocrinol Metabol 52:684-691

9. Sentongo TA, Semaeo EJ, Stettler N, Piccoli DA, Stallings VA, Zemel BS (2002) Vitamin D status in children, adolescents, and young adults with Crohn disease. Am J Clin Nutr 76:10771081

10. Kuwabara A, Tanaka K, Tsugawa N, Nakase H, Tsuji H, Shide K, Kamao M, Chiba T, Inagaki N, Okano T, Kido S (2009) High prevalence of vitamin $\mathrm{K}$ and $\mathrm{D}$ deficiency and decreased BMD in inflammatory bowel disease. Osteoporos Int 20:935-942

11. Lennard-Jones JE (1989) Classification of inflammatory bowel disease. Scand J Gastroenterol Suppl 170:2-6, discussion 16-19

12. Wendel-Vos GC, Schuit AJ, Saris WH, Kromhout D (2003) Reproducibility and relative validity of the short questionnaire to assess health-enhancing physical activity. J Clin Epidemiol 56:1163-1169

13. Clara I, Lix LM, Walker JR, Graff LA, Miller N, Rogala L, Rawsthorne P, Bernstein CN (2009) The Manitoba IBD index: evidence for a new and simple indicator of IBD activity. Am J Gastroenterol 104:1754-1763. doi:10.1038/ajg.2009.197

14. McCarthy D, Duggan P, O'Brien M, Kiely M, McCarthy J, Shanahan F, Cashman KD (2005) Seasonality of vitamin D status and bone turnover in patients with Crohn's disease. Aliment Pharmacol Ther 21:1073-1083. doi:10.1111/j.1365-2036.2005.02446.x

15. Bischoff-Ferrari HA (2008) Optimal serum 25-hydroxyvitamin D levels for multiple health outcomes. Adv Exp Med Biol 624:5571. doi:10.1007/978-0-387-77574-6_5

16. Holick MF (2008) The vitamin D deficiency pandemic and consequences for nonskeletal health: mechanisms of action. Mol Aspects Med 29:361-368. doi:10.1016/j.mam.2008.08.008

17. Gezondheidsraad (2008) Naar een toereikende inname van vitamine D. Den Haag: Gezondheidsraad "ISBN 978-90-5549-729-4"

18. Hintzpeter B, Mensink GB, Thierfelder W, Muller MJ, ScheidtNave C (2008) Vitamin D status and health correlates among German adults. Eur J Clin Nutr 62:1079-1089. doi:10.1038/sj. ejcn. 1602825

19. Hypponen E, Power C (2007) Hypovitaminosis D in British adults at age $45 \mathrm{y}$ : nationwide cohort study of dietary and lifestyle predictors. Am J Clin Nutr 85:860-868

20. Holick MF (2004) Sunlight and vitamin D for bone health and prevention of autoimmune diseases, cancers, and cardiovascular disease. Am J Clin Nutr 80:1678S-1688S

21. Vieth R (ed) (2005) The pharmacology of vitamin D, including fortification strategies. Elsevier, Amsterdam

22. Holick MF (2007) Vitamin D deficiency. N Engl J Med 357:266281. doi:10.1056/NEJMra070553

23. Grimnes G, Almas B, Eggen AE, Emaus N, Figenschau Y, Hopstock L, Hutchinson M, Methlie P, Mihailova A, Sneve M, Torjesen P, Wilsgaard T, Jorde R (2010) Effect of smoking on the serum levels of 25-hydroxyvitamin $\mathrm{D}$ depends on the assay employed. Eur J Endocrinol. doi:10.1530/EJE-10-0150

24. Melamed ML, Michos ED, Post W, Astor B (2008) 25hydroxyvitamin D levels and the risk of mortality in the general population. Arch Intern Med 168:1629-1637. doi:10.1001/ archinte.168.15.1629 
25. Jorgensen SP, Agnholt J, Glerup H, Lyhne S, Villadsen GE, Hvas CL, Bartels LE, Kelsen J, Christensen LA, Dahlerup JF (2010) Clinical trial: vitamin D3 treatment in Crohn's disease-a randomized double-blind placebo-controlled study. Aliment Pharmacol Ther 32:377-383. doi:10.1111/j.1365-2036.2010.04355.x

26. Bischoff-Ferrari HA, Dawson-Hughes B, Staehelin HB, Orav JE, Stuck AE, Theiler R, Wong JB, Egli A, Kiel DP, Henschkowski J (2009) Fall prevention with supplemental and active forms of vitamin D: a meta-analysis of randomised controlled trials. BMJ 339:b3692. doi:10.1136/bmj.b3692

27. Sanders KM, Stuart AL, Williamson EJ, Simpson JA, Kotowicz MA, Young D, Nicholson GC (2010) Annual high-dose oral vitamin $\mathrm{D}$ and falls and fractures in older women: a randomized controlled trial. JAMA 303:1815-1822. doi:10.1001/jama.2010.594

28. Broe KE, Chen TC, Weinberg J, Bischoff-Ferrari HA, Holick MF, Kiel DP (2007) A higher dose of vitamin d reduces the risk of falls in nursing home residents: a randomized, multiple-dose study. J Am Geriatr Soc 55:234-239. doi:10.1111/j.1532-5415.2007.01048.x

29. Bischoff-Ferrari HA, Staehelin HB (2008) Importance of vitamin D and calcium at older age. Int J Vitam Nutr Res 78:286-292. doi:10.1024/0300-9831.78.6.286

30. Leidig-Bruckner G, Roth HJ, Bruckner T, Lorenz A, Raue F, Frank-Raue K (2010) Are commonly recommended dosages for vitamin D supplementation too low? Vitamin D status and effects of supplementation on serum 25-hydroxyvitamin D levels-an observational study during clinical practice conditions. Osteoporos Int. doi:10.1007/s00198-010-1214-5

31. Bischoff-Ferrari HA, Shao A, Dawson-Hughes B, Hathcock J, Giovannucci E, Willett WC (2009) Benefit-risk assessment of vitamin D supplementation. Osteoporos Int. doi:10.1007/s00198-009-1119-3

32. Clarke K, Sagunarthy R, Kansal S (2008) RDW as an additional marker in inflammatory bowel disease/undifferentiated colitis. Dig Dis Sci 53:2521-2523. doi:10.1007/s10620-007-0176-8

33. Lippi G, Targher G, Montagnana M, Salvagno GL, Zoppini G, Guidi GC (2009) Relation between red blood cell distribution width and inflammatory biomarkers in a large cohort of unselected outpatients. Arch Pathol Lab Med 133:628-632

34. Froicu M, Weaver V, Wynn TA, McDowell MA, Welsh JE, Cantorna MT (2003) A crucial role for the vitamin D receptor in experimental inflammatory bowel diseases. Mol Endocrinol 17:2386-2392. doi:10.1210/me.2003-0281

35. Forman JP, Curhan GC, Taylor EN (2008) Plasma 25hydroxyvitamin D levels and risk of incident hypertension among young women. Hypertension 52:828-832. doi:10.1161/HYPER TENSIONAHA.108.117630

36. Giovannucci E (2009) Vitamin D and cardiovascular disease. Curr Atheroscler Rep 11:456-461

37. Garland CF, Gorham ED, Mohr SB, Grant WB, Giovannucci EL, Lipkin M, Newmark H, Holick MF, Garland FC (2007) Vitamin D and prevention of breast cancer: pooled analysis. J Steroid Biochem Mol Biol 103:708-711. doi:10.1016/j.jsbmb.2006.12.007

38. Gouni-Berthold I, Krone W, Berthold HK (2009) Vitamin D and cardiovascular disease. Curr Vasc Pharmacol 7:414-422

39. Cantorna MT, Zhu Y, Froicu M, Wittke A (2004) Vitamin D status, 1, 25-dihydroxyvitamin D3, and the immune system. Am J Clin Nutr 80:1717S-1720S

40. Joseph AJ, George B, Pulimood AB, Seshadri MS, Chacko A (2009) $25(\mathrm{OH})$ vitamin D level in Crohn's disease: association with sun exposure \& disease activity. Indian J Med Res 130:133137

41. Lagishetty V, Misharin AV, Liu NQ, Lisse TS, Chun RF, Ouyang Y, McLachlan SM, Adams JS, Hewison M (2010) Vitamin D deficiency in mice impairs colonic antibacterial activity and predisposes to colitis. Endocrinology 151:2423-2432. doi:10.1210/en.2010-0089

42. Peyrin-Biroulet L, Oussalah A, Bigard MA (2009) Crohn's disease: the hot hypothesis. Med Hypotheses 73:94-96. doi:10.1016/j.mehy.2009.01.022

43. Wu S, Liao AP, Xia Y, Li YC, Li JD, Sartor RB, Sun J (2010) Vitamin D receptor negatively regulates bacterial-stimulated NF- $\kappa B$ activity in intestine. Am J Pathol. doi:10.2353/ajpath.2010.090998

44. Miheller P, Muzes G, Hritz I, Lakatos G, Pregun I, Laszlo Lakatos P, Herszenyi L, Tulassay Z (2009) Comparison of the effects of 1,25 dihydroxyvitamin $\mathrm{D}$ and 25 hydroxyvitamin $\mathrm{D}$ on bone pathology and disease activity in Crohn's disease patients. Inflamm Bowel Dis. doi:10.1002/ibd.20947

45. Tilg H, Moschen AR, Kaser A, Pines A, Dotan I (2008) Gut, inflammation and osteoporosis: basic and clinical concepts. Gut 57:684-694. doi:10.1136/gut.2006.117382

46. Imaz I, Zegarra P, Gonzalez-Enriquez J, Rubio B, Alcazar R, Amate JM (2009) Poor bisphosphonate adherence for treatment of osteoporosis increases fracture risk: systematic review and metaanalysis. Osteoporos Int. doi:10.1007/s00198-009-1134-4

47. Christakos S, Ajibade DV, Dhawan P, Fechner AJ, Mady LJ (2010) Vitamin D: metabolism. Endocrinol Metab Clin North Am 39:243-253. doi:10.1016/j.ecl.2010.02.002, table of contents 